\title{
Protective effect of recombinant staphylococcal enterotoxin A entrapped in polylactic-co-glycolic acid microspheres against Staphylococcus aureus infection
}

Liben Chen ${ }^{1,2+}$, Shuang $\mathrm{Li}^{1,3+}$, Zhengfang Wang ${ }^{4}$, Ruilong Chang ${ }^{1,3}$, Jingliang $\mathrm{Su}^{3^{*}}$ and Bo Han ${ }^{1^{*}}$

\begin{abstract}
Staphylococcus aureus is an important cause of nosocomial and community-acquired infections in humans and animals, as well as the cause of mastitis in dairy cattle. Vaccines aimed at preventing $S$. aureus infection in bovine mastitis have been studied for many years, but have so far been unsuccessful due to the complexity of the bacteria, and the lack of suitable vaccine delivery vehicles. The current study developed an Escherichia coli protein expression system that produced a recombinant staphylococcal enterotoxin A (rSEA) encapsulated into biodegradable microparticles generated by polylactic-co-glycolic acid (PLGA) dissolved in methylene chloride and stabilized with polyvinyl acetate. Antigen loading and surface properties of the microparticles were investigated to optimize particle preparation protocols. The prepared PLGA-rSEA microspheres had a diameter of approximately 5 $\mu \mathrm{m}$ with a smooth and regular surface. The immunogenicity of the PLGA-rSEA vaccine was assessed using mice as an animal model and showed that the vaccine induced a strong humoral immune response and increased the percent survival of challenged mice and bacterial clearance. Histological analysis showed moderate impairment caused by the pathogen upon challenge afforded by immunization with PLGA-rSEA microspheres. Antibody titer in the sera of mice immunized with PLGA-rSEA microparticles was higher than in vaccinated mice with rSEA. In conclusion, the PLGA-rSEA microparticle vaccine developed here could potentially be used as a vaccine against enterotoxigenic S. aureus.
\end{abstract}

\section{Introduction}

Staphylococcus aureus (S. aureus) is an important cause of nosocomial and community-acquired infections in humans and animals, and economic loss in animal husbandry, such as mastitis in dairy cattle [1]. S. aureus can provoke clinical mastitis but more frequently causes subclinical infections that tend to become chronic and difficult to eradicate by conventional antimicrobial therapies $[2,3]$.

\footnotetext{
*Correspondence: suzhang@cau.edu.cn; hanbo@cau.edu.cn

+ Contributed equally

'Department of Clinical Medicine, College of Veterinary Medicine, China Agricultural University, Beijing 100193, China

${ }^{3}$ Key Laboratory of Animal Epidemiology and Zoonosis of the Ministry of Agriculture, College of Veterinary Medicine, China Agricultural University, Beijing 100193, China

Full list of author information is available at the end of the article
}

The frequent incapacity of both the antibiotics and immune response to prevent infection and destroy the pathogen in the intramammary environment explains why S. aureus bovine mastitis constitutes a major challenge to dairy producers [4]. Multidrug-resistant S. aureus infections continue to increase, and some strains respond to few, if any, conventional antibiotic therapies. Hence, interest in immunotherapeutic strategies, either passive or active, has seen resurgence in recent years. The pathogenicity of $S$. aureus results from structures that allow it to avoid phagocytosis, the production of enzymes and toxins, including exotoxins such as staphylococcal enterotoxins (SE), toxic shock syndrome toxins (TSST), exoenzymes, adhesins, and numerous cell-associated components that either directly cause disease or facilitate tissue penetration and immune cell recruitment $[5,6]$. Therefore, application
C Biomed Central

(c) 2012 Chen et al; licensee BioMed Central Ltd. This is an Open Access article distributed under the terms of the Creative Commons Attribution License (http://creativecommons.org/licenses/by/2.0), which permits unrestricted use, distribution, and reproduction in any medium, provided the original work is properly cited. 
of efficacious vaccine is one of the most important prophylactic measures against bovine mastitis.

Several studies have recently focused on $S$. aureus toxins as vaccine targets [7-9]. SE, which are bacterial superantigens (sAg) produced by $S$. aureus, play an important role in establishing and maintaining infection [5]. Immunization with recombinant or mutant staphylococcal enterotoxin A (SEA) [10], staphylococcal enterotoxin B (SEB) [11-13], and TSST-1 [12,14] can elicit neutralizing antibodies against wild-type SE, and has been shown to protect mice, rabbits, and monkeys against lethal shock induced by wild-type superantigenic toxins. Hu et al. have investigated a double-mutant staphylococcal enterotoxin C (SEC) [15], that was devoid of superantigenic activity, as an intranasal vaccine for protection against $S$. aureus challenge in mice. Other groups recently studied a recombinant staphylococcal enterotoxin $\mathrm{C}$ mutant in lactating dairy cattle and found that vaccinated cattle had lower milk somatic cell counts and lower numbers of intra-mammary infection than unvaccinated controls $[16,17]$.

Modern vaccines based on subunits of pathogens, such as purified proteins, are often unable to evoke strong immune responses. One of the most important challenges in the field is the selection of suitable adjuvants and delivery systems. Suitable adjuvants must enhance antigen specific immune responses, improve protection through stimulation of optimal types of immunity, and have low levels of adverse effects. Alum is currently the only adjuvant approved for human use by the United States Food and Drug Administration. Although alum has an excellent safety record, comparative studies showed that it is a poor adjuvant for recombinant proteins and DNA [18]. Additionally, alum is not effective for eliciting IgA antibody responses and some studies have even indicated that alum is associated with allergic reactions in some subjects [19].

Biodegradable and biocompatible polyesters, such as poly(lactic-co-glycolic acid) (PLGA), are one of the primary candidates for the development of microspheres as vaccines, because they have been used in humans for many years as suture material and as controlled-release delivery systems for peptide drugs [20]. One of the most attractive features of microspheres for vaccine development is their ability to control the rate of release of entrapped antigens over a longer period [21]. Ultimately, this may allow the development of single-dose vaccines through the preparation of microspheres that release entrapped antigens at times when booster doses of vaccines would normally be administered. The development of a single-dose vaccine would represent a significant advance towards the preparation of an ideal vaccine that would likely result in improved vaccine compliance, particularly for bovine mastitis.
The aims of this present study are 1) to express and purify a recombinant SEA as a vaccine candidate and to assess the efficiency of the PLGA adjuvant as a singledose delivery system; 2) to establish a mouse model to investigate whether immunization with the PLGA-SEA vaccine could protect against $S$. aureus infection.

\section{Materials and methods \\ Mice}

Six to eight-week-old female specific-pathogen-free (SPF) mice were purchased from Merial-Vital Laboratory Animal Technology (Beijing, China). All animals were fed in germ-free isolators and experiments were in compliance with the guidelines of Beijing Municipality on the Review of Welfare and Ethics of Laboratory Animals approved by the Beijing Municipality Administration Office of Laboratory Animals.

\section{Anesthesia}

Sodium pentobarbital $(50 \mathrm{mg} / \mathrm{kg}$ ) was given i.p. prior to all immunizations, collection of blood and bacterial challenge. A physical euthanasia method, cervical dislocation, was performed for collection of tissues, as previously described [22].

\section{Bacterial strain and chemical agents}

Enterotoxigenic S. aureus (ATCC13565) was purchased from the Chinese National Center for Medical Type Culture Collections. The bacteria were cultured in tryptic soy broth (TSB) at $37^{\circ} \mathrm{C}$ with agitation at $120 \mathrm{rpm}$. Escherichia coli strains were grown in Luria-Bertani (LB) broth or on LB agar plates in the presence or absence of ampicillin $(100 \mu \mathrm{g} / \mathrm{mL})$.

\section{Glutathione-S-transferase (GST)-fusion SEA protein expression}

For the amplification of the staphylococcal sea gene, primers (sea-1-774-F: 5'-CGGGATCCATGAAAAAAACAGCATTTACA-3'; sea-1-774-R: 5'-CCGCTCGAG TTAACTTGTATATAAATATATAT-3'; restriction enzyme sites underlined) were designed according to the published complete sea sequences (GenBank accession: AJ33122). The bacterial DNA was extracted by EasyPure Genomic DNAExtraction Kit (Transgen, Beijing, China). The polymerase chain reaction (PCR) assay was performed using $1 \mu \mathrm{L}$ of DNA in a total reaction volume of $20 \mu \mathrm{L}$ that contained $10 \mu \mathrm{L}$ of Taq plus master mix (Transgen), $10 \mathrm{pmol}$ of each of the two primers, and RNase-free $\mathrm{H}_{2} \mathrm{O}$. The thermal cycling parameters used were as follows: $5 \mathrm{~min}$ at $95^{\circ} \mathrm{C}$, followed by 30 cycles of $60 \mathrm{~s}$ at $94^{\circ} \mathrm{C}, 60 \mathrm{~s}$ at $45^{\circ} \mathrm{C}$, and $60 \mathrm{~s}$ at $72^{\circ} \mathrm{C}$, followed by extension for $10 \mathrm{~min}$ at $72^{\circ} \mathrm{C}$. The reaction product was visualized by agarose gel electrophoresis and further confirmed by nucleotide sequence analysis. The amplified 
sea gene was ligated to the $B a m H I / X h o I$ site of the pGEX-4 T-1 expression vector (GE Healthcare, Shanghai, China). The recombinant expression vector, pGEX-sea, was used to transform E. coli BL21 (DE3), and subsequently named pGEX-sea-BL21DE3.

The resultant recombinant E. coli strain was used to express and purify a Glutathione S-transferase (GST) fusion protein (designated rSEA) by affinity chromatography with Glutathione Sepharose 4 Fast Flow resin (Henghuibio, Beijing, China) according to the manufacturer's instructions. Protein concentration was determined by bicinchoninic acid (BCA) protein assay kit (Solarbio, Beijing, China) and analyzed by sodium dodecyl sulfate polyacrylamide gel electrophoresis (SDSPAGE) and subsequent western immunoblot of GST fusion protein visualized using an enhanced chemiluminescence (ECL) Western Blot Kit (Beyotime Institute of Biotechnology, Jiangsu, China), according to the manufacturer's instructions. Mouse anti-GST tag monoclonal antibody (M\&C Gene Technology, Beijing, China) was used as primary antibodies and horseradish peroxidase (HRP)-conjugated rabbit anti-mouse IgG (Jackson ImmunoResearch Laboratories, West Grove, PA, USA) as secondary antibodies, as described previously [23].

\section{Evaluation of the toxicity of recombinant SEA protein}

To evaluate the toxicity and safety of the rSEA protein, groups of BALB/c mice (5 mice per group) were intraperitoneally (i. p.) administered either $1 \mathrm{mg}, 100 \mu \mathrm{g}$ or $10 \mu \mathrm{g}$ rSEA protein per mouse. Mice in the negative control group were administered sterile phosphate-buffered saline (PBS; pH 7.4). The positive control group was administered i.p. $10 \mu \mathrm{g}$ highly purified SEA (Sigma-Aldrich, Shanghai, China). Mice were sacrificed 7 days after injection, and livers were removed and fixed with $10 \%$ neutralbuffered formalin for histopathological evaluation, as previously described [24].

\section{Preparation and characterization of protein-loaded microspheres}

PLGA microspheres (MS) containing rSEA were prepared by a water-in-oil-in-water (w/o/w) solvent extraction procedure, as previously reported [25]. Briefly, $100 \mathrm{~mL}$ of fusion protein (protein concentration, $5 \mathrm{mg} /$ $\mathrm{mL}$ ) was added to $500 \mathrm{mg}$ of PLGA (50:50; Daigan Biological Materials, Shandong, China) in $10 \mathrm{~mL}$ of methylene chloride. The mixture was emulsified by sonication at output $300 \mathrm{~W}$ for $60 \mathrm{~s}$ to form the water-oil (w/o) emulsion. This emulsion was then added to $40 \mathrm{~mL}$ of $5 \%$ aqueous polyvinyl alcohol (PVA, MW 31,000; SigmaAldrich) solution to form the w/o/w emulsion. The organic solvent was stirred at a moderate speed at ambient temperature for $10 \mathrm{~h}$. The rSEA-loaded MS were centrifuged at $5000 \times g$ for $45 \mathrm{~min}$ and then washed three times with double-distilled water. The MS were then lyophilized and stored at $-20^{\circ} \mathrm{C}$. Core loading of rSEA in MS was determined by digesting the MS and assaying the protein concentration [26]. Briefly, $20 \mathrm{mg}$ of MS was suspended in $2 \mathrm{~mL}$ of $2.5 \% \mathrm{SDS} / 0.2 \mathrm{M} \mathrm{NaOH}$ solution, in which the SDS ensures the complete solubilization of the protein during polymer hydrolysis, and the resulting solution was then neutralized by the stepwise addition of $1 \mathrm{M}$ hydrochloric acid. The amount of surface-associated protein was assessed by suspending the MS in PBS for 15 min, centrifuging the samples to sediment the MS, and then analyzing the supernatant for protein using the Bicinchoninic Acid (BCA) protein assay kit (Solarbio, Beijing, China).

MS size and surface morphology were examined by scanning electron microscopy (SEM; Hitachi S-3400; Hitachi, Japan). The total protein release dynamics was estimated using the BCA method $[13,27,28]$. Briefly, $100 \mathrm{mg}$ of the MS were placed in test tubes containing 1 $\mathrm{mL}$ PBS (0.01 M; pH 7.4) and were incubated at $37^{\circ} \mathrm{C}$ with rotation. At 10-day intervals, the samples were centrifuged at $10000 \times g$ for $10 \mathrm{~min}$; the supernatant was collected and assayed for protein release using the BCA assay. The release study was continued after replacement with the same volume of fresh buffer.

\section{Immunization and determination of antibody responses} by enzyme-linked immunosorbent assay (ELISA)

Groups of six female BALB/c mice (6-8 weeks old) were immunized i.p. with $100 \mu \mathrm{g}$ of PLGA-rSEA, $100 \mu \mathrm{g}$ of rSEA or $100 \mu$ g of empty PLGA. Control mice received $200 \mu \mathrm{L}$ sterile PBS. Mice were restricted and were bled from the caudal vein (about $50 \mu \mathrm{L}$ once) on days $0,7,14$, $21,28,35$, and 42 post-immunization. Serum IgG against SEA were assayed using an indirect ELISA [28]. Briefly, 96-well ELISA plates (Corning, Lowell, MA, USA) were coated with $100 \mu \mathrm{L} /$ well of a $0.5 \mu \mathrm{g} / \mathrm{mL}$ highly purified SEA (Sigma-Aldrich) in carbonate buffer $(0.01 \mathrm{M}$; $\mathrm{pH}$ 9.4) and incubated overnight at $4{ }^{\circ} \mathrm{C}$. The plates were thoroughly washed three times with PBS containing 0.05\% Tween-20 (PBS-T; pH 7.4) and treated with blocking buffer (5\% skim milk in PBS-T) at $37^{\circ} \mathrm{C}$ for $2 \mathrm{~h}$. After washing, $100 \mu \mathrm{L}$ of mouse serum (diluted 1:200 in PBST) was added to each well and incubated at $37^{\circ} \mathrm{C}$ for $1 \mathrm{~h}$. After incubation, the plates were washed three times and $100 \mu \mathrm{L}$ of HRP-conjugated goat anti-mouse IgG (Jackson ImmunoResearch Laboratories) was added to each well. The plates were incubated for $1 \mathrm{~h}$ at $37^{\circ} \mathrm{C}$ and washed three times. To develop the plates, $100 \mu \mathrm{L} /$ well tetramethylbenzidine substrate solution was added to each well and incubated at $37^{\circ} \mathrm{C}$ for $15 \mathrm{~min}$ and stopped with $2 \mathrm{M} \mathrm{H}_{2} \mathrm{SO}_{4}$. The plates were read at $450 \mathrm{~nm}$ on an ELISA reader (Thermo Fisher Scientific Inc., Shanghai, China) and the results were reported as the $\mathrm{OD}_{450}$ of test 
well/OD 450 of the control well (mouse serum from the control group) $(\mathrm{P} / \mathrm{N})[28]$.

\section{Challenge studies}

Six weeks after immunization as above, five mice from each group were inoculated i.p. with S. aureus (ATCC13565) at the lethal dosage of $2 \times 10^{9}$ colony forming units (CFU; $2 \mathrm{LD}_{50}$ ). Infected mice were monitored daily for mortality for 10 days.

\section{Bacterial burden and histopathological analysis}

Two groups of mice (12 mice per group), immunized with either rSEA or PBS, were injected i.p. with sublethal doses of $S$. aureus $\left(10^{8} \mathrm{CFU}, 0.1 \mathrm{LD}_{50}\right)$ and sacrificed 4 times on days 1, 3, 5, and 7 post-infection. Livers and spleens were aseptically removed and homogenized individually in $1 \mathrm{~mL}$ of sterile PBS. The viable bacterial levels were enumerated by plating the serially diluted homogenates on TSA medium. For histopathological evaluation, three immunized mice were sacrificed to excise the liver, spleen, and kidney on day 9 after infection. Organs were fixed in 10\% neutral-buffered formalin and processed using standard histological methods as above.

\section{Statistical analysis}

Data for the determination of bacterial burden and antibody level were expressed as mean \pm standard error of the mean, and all the test groups were compared to the control group using the Student's $t$ test. A $P$-value of $<0.05$ was considered significant. Kaplan-Meier Log Rank methods were used for analyses of survival data. All statistics were performed using the Origin software (version 8.0; OriginLab, Northampton, MA, USA).

\section{Results}

\section{Gene cloning and rSEA preparation}

The sea gene isolated from S. aureus ATCC 13565 was sequenced to ensure that there were no mutations introduced during PCR amplification. SDS-PAGE showed that the GST-SEA fusion protein had a relative molecular mass of approximately $56 \mathrm{kDa}$ expressed by the pGEX-seaBL21DE3 strain (Figure 1a). The expressed protein was also demonstrated by western immunoblot (Figure 1b).

\section{Toxicity evaluation}

In order to ensure that the fusion SEA was safe when administered as a vaccine, mice were injected i.p. with different dosages of the recombinant protein. None of the mice in the four groups showed any significant clinical symptoms during the experiment period. However, mice that received the high dose of rSEA (1 mg/mouse) (Figure 1f) and low dose of highly purified SEA group (10 $\mathrm{gg} /$ mouse) (Figure 1d) exhibited mild liver damage, by histological examination. Focal necrosis of hepatocytes and macrophage infiltration were obvious (Figure 1d, f). No pathological change was observed in other groups (Figure 1e). Therefore, the rSEA showed no significant toxicity in the low dosage range $(<100 \mu \mathrm{g})$ in mice.

\section{Characterization of PLGA microspheres}

The PLGA entrapped rSEA MS exhibited a size range from 1-5 $\mu \mathrm{m}$ in diameter with smooth surface under SEM (Figure 2a). The protein loading level of the MS was calculated by the amount of rSEA in a given weight of the polymer MS. The protein concentration in the MS was determined by BCA assay and showed a 78\% loading level of the rSEA. The in vitro release kinetics of the rSEA was evaluated via BCA assay (Figure 2b), showing that rSEA was released over time. We found that rSEA had a sustained release from the MS after 20 days and released approximately $50 \%$ of loading dose in 50 days during polymer hydrolysis.

\section{Antibody response in mice}

The SEA-specific antibody responses induced by PLGA encapsulated rSEA were tested after i.p. administration. For comparison, groups of mice were immunized with non-adjuvanted rSEA and empty PLGA MS. Serum samples were collected at 7-day intervals. Antibodies developed against the SEA in serum were detected by indirect ELISA. From the fourth week after immunization, the MS vaccine induced significantly high antibody responses. Antibody response of the PLGA-rSEA group was higher than that of the rSEA group indicating that the MS adjuvant enhanced the immunogenicity of rSEA (Figure 3).

\section{Immuno-protection against bacterial infection}

To determine whether the vaccine induced protection against $S$. aureus infection, groups of mice were inoculated with the MS entrapped with rSEA, or PBS, and then challenged with appropriate doses of $S$. aureus. When challenged with a lethal dose of S. aureus, $80 \%(4 / 5)$ of the unvaccinated mice died within 2 days post-infection (Figure 4a). However, $100 \%$ of the mice vaccinated with the microsphere vaccine survived.

It was next determined whether the increased survival in rSEA immunized mice was due to control of bacterial growth and dissemination during infection. Immunizedand sham-control mice were challenged with $10^{8} \mathrm{CFU} /$ mouse and bacterial burden in livers and spleens were determined. Significant differences in CFU were observed from day 3 pi (Figure 4b, c). No bacteria were recovered from spleens of all mice on day 7 (Figure 4c).

Histopathological analyses were performed with vaccinated and unvaccinated mice 9 days after challenge (Figure 5). Vaccinated mice exhibited no obvious pathological change in the liver, spleen, and kidney (Figure $5 \mathrm{a}, \mathrm{c}, \mathrm{e})$. However, the livers of sham-vaccinated mice 

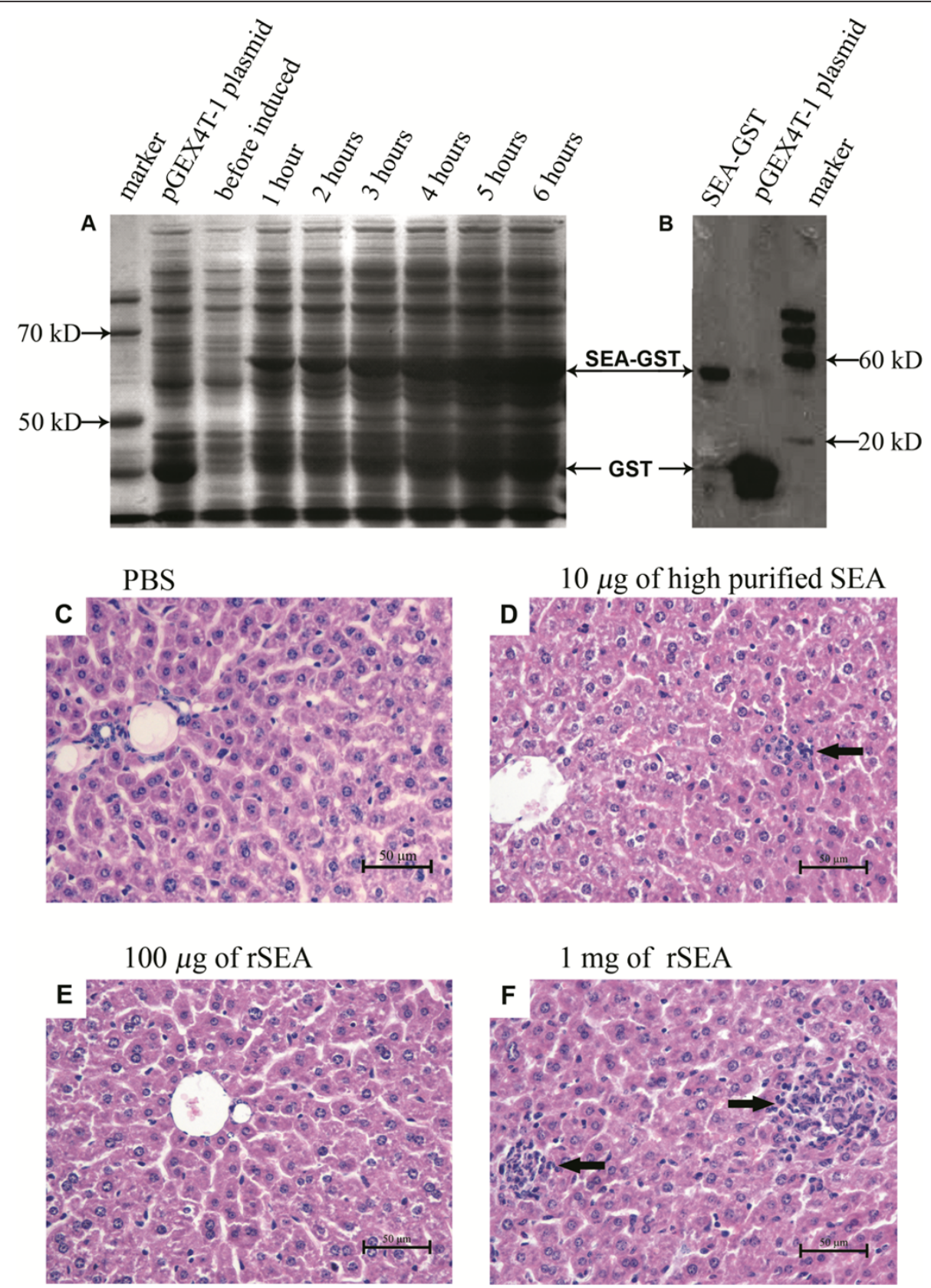

Figure 1 SEA expression and toxicity analysis. (A) SDS-PAGE for the rSEA induced by IPTG (1 mM) at different times; (B) Western immunoblot for rSEA protein, using anti-GST as the capture antibody; (C) histological imaging of liver sections from mice injected with PBS, (D) from mice injected with highly purified SEA protein, (E) low dose of rSEA experimental group, and (F) high dose of rSEA. Black arrows in D \& F indicate the focal necrosis of hepatocytes and macrophage infiltration.

showed moderate infiltration of mononuclear cells around the central veins (Figure $5 \mathrm{~b}$ ). In the spleen, lymphoid follicles were markedly decreased, and numerous erythrocytes and macrophages appeared in the white pulp (Figure 5d). Additionally, dilatation and hyperemia was demonstrated in Bowman's capsules of the kidney. Necrotic and scaled tubular structure was also observed
(Figure 5f). These results show that using PLGA-SEA could protect mice against $S$. aureus infection.

\section{Discussion}

S. aureus is a representative pathogen that can produce a number of potential virulence factors, including hemolysins, coagulase, leukocidin, enterotoxins, and TSST-1. 

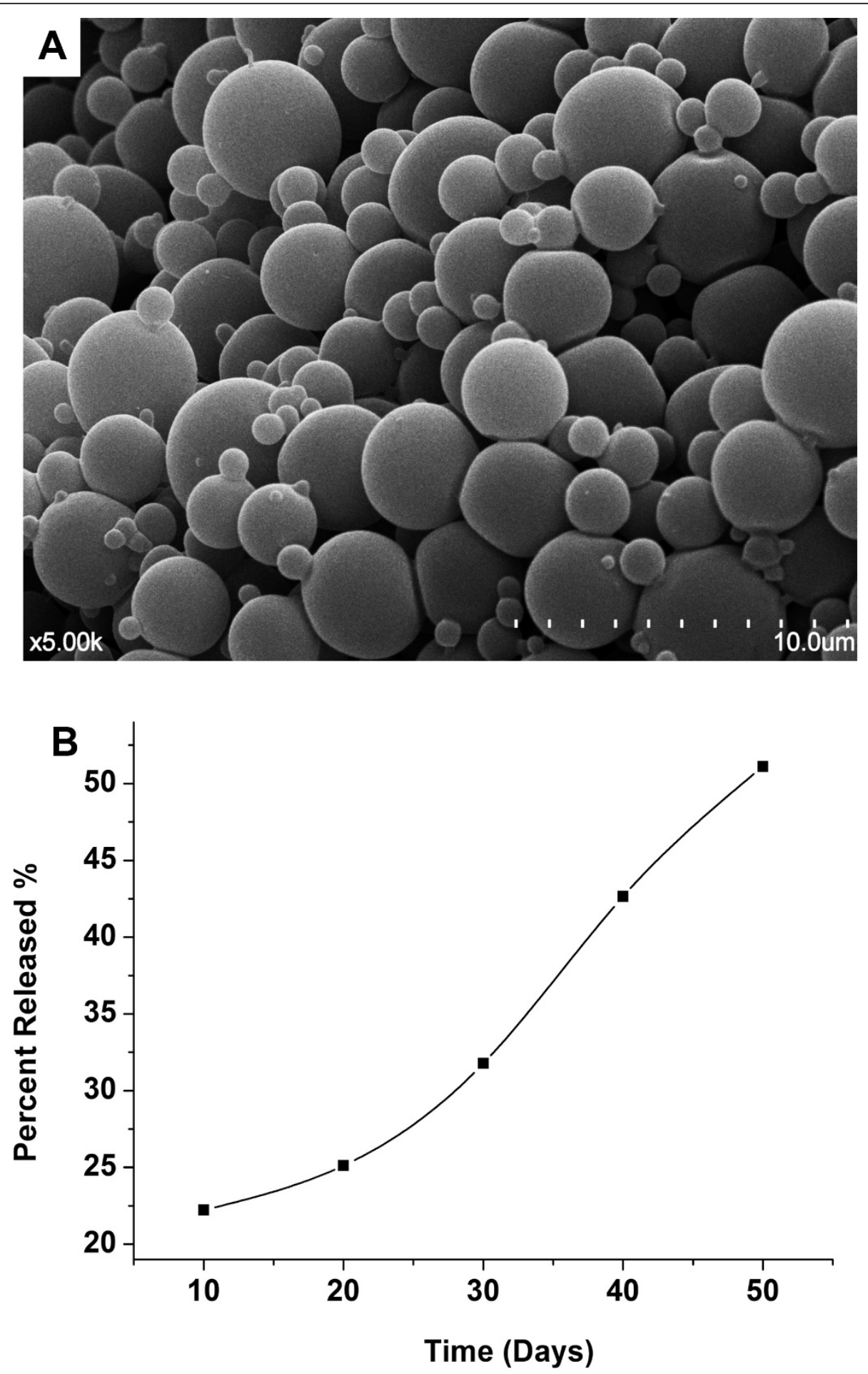

Figure 2 Characteristics of the PLGA-rSEA. (A) Scanning electron microscopy (SEM) photograph of PLGA-rSEA. Microsphere size, morphology, and surface appearance were examined by SEM. (B) Antigen-release kinetics. Percentage of released antigen was detected by BCA assay from day $10-50$.

The degree of severity of infection caused by $S$. aureus, which is related to these factors to some extent, may also vary among different strains of $S$. aureus [29]. It has been postulated that persistent infection with $S$. aureus is associated with an impaired immune response, which is also mediated by factors produced by $S$. aureus. Previous studies have investigated the role of $S$. aureus exosecretions in bovine udders by intracisternally 


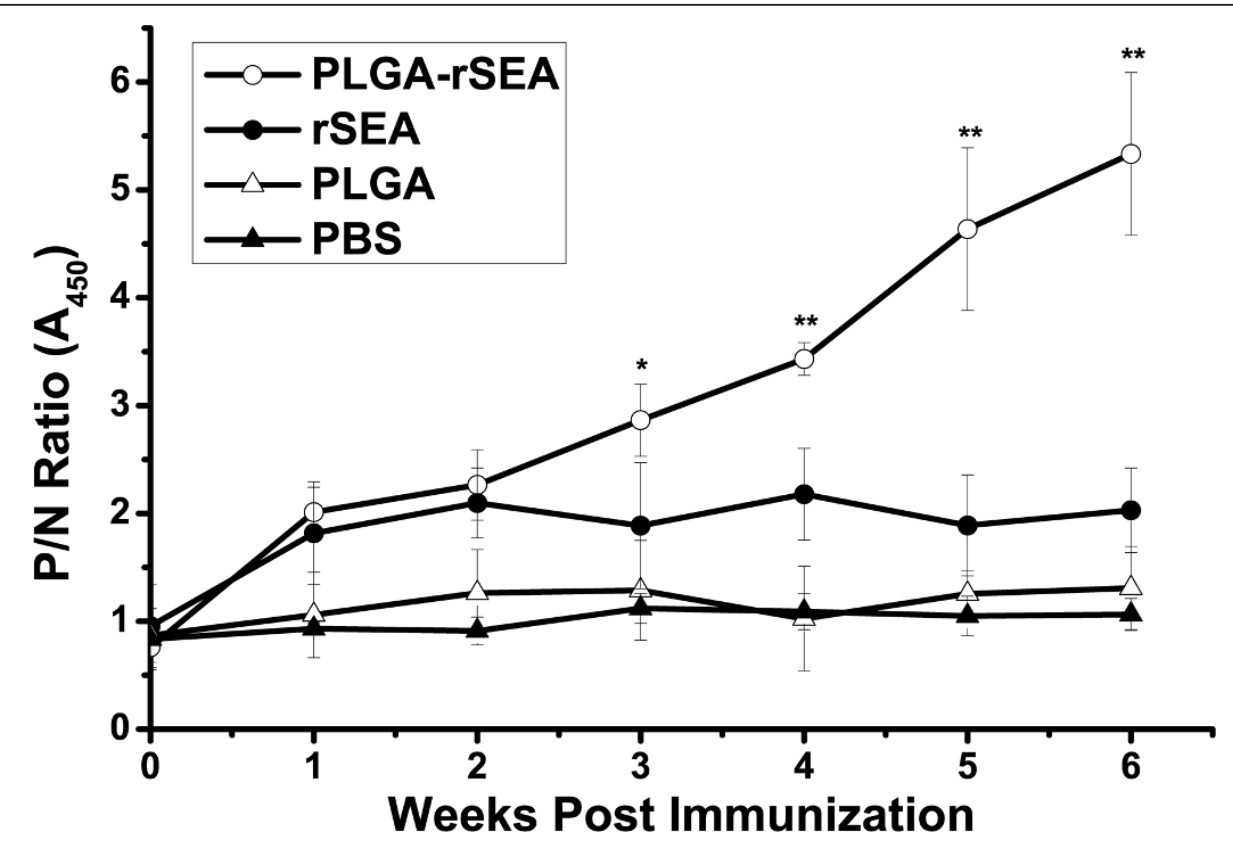

Figure 3 Serum antibody analysis. Antibody levels in mice serum. Sera were collected from vaccinated and unvaccinated controls as described in the text. The error bars indicate standard errors of the means for five mice per group. The asterisks indicate $P$ values $\left(^{*}, P<0.05 ;{ }^{* *}\right.$, $P<0.01$, compared with the PBS group).

inoculating them with sterile bacterial exosecretions from various strains of $S$. aureus [30,31].

SE have many distinct biological activities and can escape from normal host adaptive immune responses. For example, SE have the ability to bind to the major histocompatibility class II (MHC-II) molecules and specific $\mathrm{V}$-segments of T-cell receptors (TCR) outside the binding groove that are associated with MHC-restricted immune system recognition of processed peptides. The binding of SAg to MHC-II and TCR stimulates abnormally large numbers of $\mathrm{T}$ cells. SE exert various deleterious effects, including induction of shock, cytokine induction, T-cell unresponsiveness and clonal deletion, differential stimulation of $\mathrm{CD} 4^{+}$and $\mathrm{CD} 8^{+} \mathrm{T}$-cell subsets, and B-cell differentiation [30-32]. Although largely unconfirmed, in cases of bovine mastitis, there is a clear potential for SE to modulate immune responses and contribute to the virulence and persistence of $S$. aureus in cattle [17].

SE are believed to be related to common biological activities of toxins, which include pyrogenicity, immune response suppression, cytokine induction, proliferation of lymphocytes, and superantigenicity. Such biological activity plays an important role in lethal diseases, such as toxic shock syndrome. If the amino acid sequence of these functional structures is deleted or substituted with another amino acid sequence, SE can be used as vaccines or therapies in humans or animals. Bavari et al. [10] demonstrated that rSEA refers to SEA that has been mutated in the class II binding site and was safely used as a vaccine, which was also proved in a study performed by Collins et al. [33].

The N- and C-terminal peptides of SEA are important sites for interaction with MHC-II molecule or TCR. In the current study, the production of a recombinant expression vector containing the sea gene linked with the GST gene at the 5'-end suggests that the rSEA is altered leading to the loss of MHC-II and TCR binding sites. The reduction in toxicity compared to the native protein in this study suggests that it has reduced superantigenic activity, but further experiments are required to confirm that this is the case. Admittedly, further studies on rSEA toxicity through other aspects and in other animals, such as cattle and humans, should be performed for practical use of the rSEA based vaccines.

The use of polymeric MS as vaccine adjuvants and delivery systems has been investigated for their many advantages $[34,35]$. It has been demonstrated that a stronger immune response is elicited when an antigen is associated with MS compared with a soluble antigen alone. The delivery system controls the release of the entrapped antigens slowly and continuously. The most significant feature of a PLGA vaccine is the one-dose administration [36,37], and this was confirmed in the current study. The effect of particle size on immunogenicity is likely to be a consequence of enhanced uptake into the lymphatics and greater uptake into antigen-presenting cells for the smaller sized particles, since only MS $<5 \mu \mathrm{m}$ were proven to be 

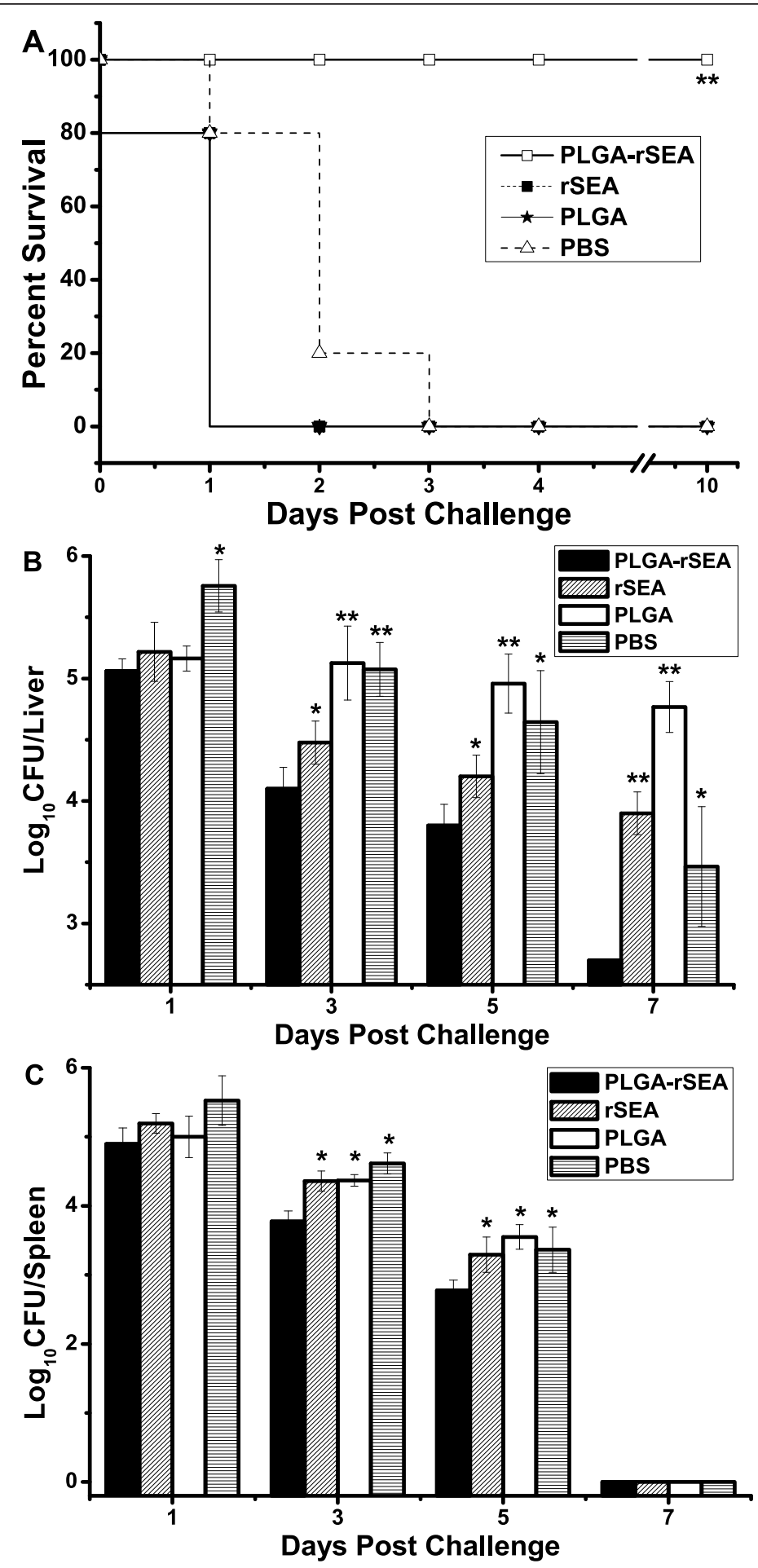

Figure 4 In vivo evaluation of the PLGA-rSEA vaccine protection. (A) Percent survival after infection; (B) In vivo growth of S. aureus in the liver after challenge; (C) In vivo growth of S. aureus in the spleen after challenge. BALB/c mice were vaccinated with PLGA-rSEA and then challenged i.p. with $10^{8} \mathrm{CFU}$ of S. aureus for bacterial clearance analysis (A and B) and $10^{9} \mathrm{CFU}$ lethal doses of S. aureus for percent survival analysis (C) ${ }^{*}, P<0.05 ; * *, P<0.01$, compared with the PBS group). 

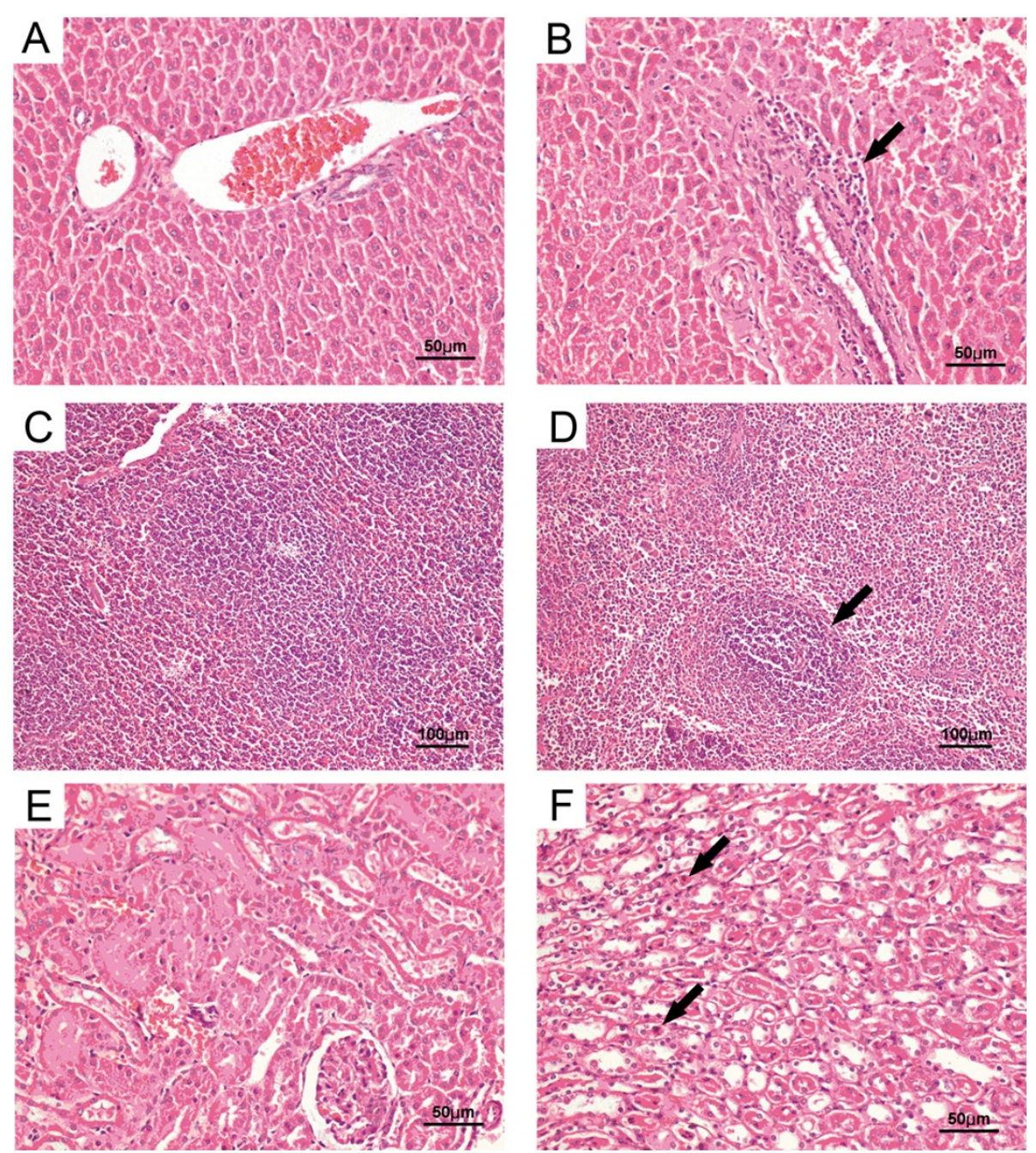

Figure 5 Histological analysis of mice after challenge with S. aureus. (A) Liver histopathology from mice challenged with S. aureus after vaccination with PLGA-rSEA. (B) Liver histopathology of unvaccinated mice challenged with S. aureus. The black arrow indicates moderate infiltration of mononuclear cells around the central veins (C) Spleen histopathology of mice immunized with PLGA-rSEA. (D) Spleen

histopathology of unvaccinated mice. (E) Kidney histopathology of mice immunized with PLGA-rSEA. The black arrow indicates erythrocytes and macrophages in the white pulp. (F) Kidney histopathology of unvaccinated mice. BALB/c mice were vaccinated and then challenged i.p. with $10^{8}$ CFU of S. aureus six weeks after immunization. Mice were sacrificed on day 9 after challenge for this analysis. Tissues were stained with

hematoxylin and eosin. Black arrows indicate the necrotic and scaled of the tubular structure.

transported to the spleen [38]. The choice of the type of polymer is dependent on the actual needs of the antigen delivery system. The erosion of the polymer is dependent on two main parameters, molecular weight and monomer ratios; the higher the molecular weight of the polymer, the longer the time it will need to erode in vivo, and therefore will have a slower release. Also, the monomer ratios of lactic acid and glycolic acid in the polymer backbone affect erosion. Higher lactic acid content slows erosion rates in comparison to higher glycolic acid content. In the current study, polymers with molecular weight of $100 \mathrm{kDa}$, which is ideal for a two-month delivery time, were used to form the MS. This is consistent with other published work [20,27].

To prepare antigen entrapped MS, a certain amount of polymer is required to be present to ensure complete entrapment of the antigen within the particle. A 4-6\% polymer solution is ideal for making small MS $(<10 \mu \mathrm{m})$ [25]; thus, we used a $5 \%$ polymer solution to prepare the MS. As observed by SEM (Figure 2a), the particle size of MS were between 1-5 $\mu \mathrm{m}$.

Currently, vaccine efficacy against $S$. aureus is defined as an increase in the spontaneous cure rate [39-42]. In our study, antibody experiments showed a significantly 
high anti-SEA antibody titer giving protection against $S$. aureus. Lethal-dose experiments demonstrated that the PLGA-rSEA vaccine increased percent survival at a high dose $\left(10^{9} \mathrm{CFU} / \mathrm{mouse}\right)$ of $\mathrm{S}$. aureus and histological tests proved that this vaccine caused less pathological damage at a lower dose $\left(10^{8} \mathrm{CFU} /\right.$ mouse $)$ of this enterotoxigenic strain. Further, the PLGA adjuvant stimulated the host humoral immune response (Figure 5). However, no significantly increased differentiation of either $\mathrm{CD} 4^{+}$ or $\mathrm{CD}^{+}$cells after vaccination were observed in our study according to flow cytometric assays (data not shown), although some published work proved that the cell-mediated immune response could be enhanced by PLGA adjuvant [43-46]. Therefore, further investigation is necessary to fully understand how the PLGA particles interact with the cell-mediated immune system. Due to the protective efficiency of the PLGA-rSEA MS vaccine developed in this study, we suggest that it should be possible to develop a subunit vaccination approach associated with PLGA MS for effective antibody-mediated protection against $S$. aureus. However, given the nature of $S$. aureus and the lessons learned from the recent failure of some emerging vaccines in phase III trials [47], it is clear that a multi-component vaccine is essential. Studies presented here indicate a positive approach to developing an efficient multi-component bovine mastitis vaccine that may contain different enterotoxins and other binding proteins associated with the high performance adjuvant, PLGA. This vaccine will be a promising strategy for preventing $S$. aureus caused bovine mastitis, because single dose administration presents significant superiority in treating dairy cows.

In conclusion, our strategy to combine rSEA with 5\% PLGA polymer solution making $5 \mu \mathrm{m}$ microspheres as a vaccine with a one-dose administration for two-month delivery proved to be a good inducer of immune responses against $S$. aureus infection in the mouse model. It produced high anti-SEA antibody titer and percent survival, as well as less pathological damage. These preliminary data are encouraging and underline the feasibility of a protective vaccine.

\section{Acknowledgements}

The current research was supported by the Chinese Eleventh "Five-year" National Science and Technology Support Project (No. 2006BAD04A05), the National Basic Research Program of China (Project 973 No. 2010CB530303), Specialized Research Fund for the Doctoral Program of Higher Education (No. 20060019045) and Beijing Elitist Support Project (2011D002006000001).

\section{Author details}

${ }^{1}$ Department of Clinical Medicine, College of Veterinary Medicine, China Agricultural University, Beijing 100193, China. ${ }^{2}$ Beijing Veterinary Diagnostic Institute, Beijing 100101, China. ${ }^{3}$ Key Laboratory of Animal Epidemiology and Zoonosis of the Ministry of Agriculture, College of Veterinary Medicine, China Agricultural University, Beijing 100193, China. ${ }^{4}$ Department of Chemistry and Biochemistry, Ohio University, Athens 45701, OH, USA.

\section{Authors' contributions}

$\mathrm{BH}$ conceived the study, and participated in its design, coordination, contributed to the analysis of the results and preparation of initial and revised manuscript versions. LBC, SL, ZFW participated in designing of the experimental strategy, carried out the glutathione-S-transferase (GST)-fusion SEA protein expression, evaluation of the toxicity of recombinant SEA protein, preparation and characterization of protein-loaded microspheres, immunization and determination of antibody responses, Bacterial burden and histopathological analysis; RLC carried out the challenge studies; JLS participated in the design of the study and contributed to the preparation of the manuscript. All authors read and approved the final manuscript.

\section{Competing interests}

The authors declare that they have no competing interests.

Received: 5 October 2011 Accepted: 19 March 2012

Published: 19 March 2012

\section{References}

1. Ruegg PL: Investigation of mastitis problems on farms. Vet Clin North Am Food Anim Pract 2003, 19:47-73.

2. Wilson DJ, Gonzalez RN, Das HH: Bovine mastitis pathogens in New York and Pennsylvania: prevalence and effects on somatic cell count and milk production. J Dairy Sci 1997, 80:2592-2598.

3. Zecconi A, Piccinini R, Fox LK: Epidemiologic study of intramammary infections with Staphylococcus aureus during a control program in nine commercial dairy herds. J Am Vet Med Assoc 2003, 223:684-688.

4. Brouillette E, Malouin F: The pathogenesis and control of Staphylococcus aureus-induced mastitis: study models in the mouse. Microbes Infect 2005, 7:560-568.

5. Dinges MM, Orwin PM, Schlievert PM: Exotoxins of Staphylococcus aureus. Clin Microbiol Rev 2000, 13:16-34.

6. Harro JM, Peters BM, O'May GA, Archer N, Kerns P, Prabhakara R, Shirtliff ME: Vaccine development in Staphylococcus aureus: taking the biofilm phenotype into consideration. FEMS Immunol Med Microbiol 2010, 59:306-323.

7. Bubeck Wardenburg J, Schneewind O: Vaccine protection against Staphylococcus aureus pneumonia. J Exp Med 2008, 205:287-294.

8. Bubeck Wardenburg J, Patel RJ, Schneewind O: Surface proteins and exotoxins are required for the pathogenesis of Staphylococcus aureus pneumonia. Infect Immun 2007, 75:1040-1044.

9. DeLeo FR, Otto M: An antidote for Staphylococcus aureus pneumonia? J Exp Med 2008, 205:271-274

10. Bavari S, Dyas B, Ulrich RG: Superantigen vaccines: a comparative study of genetically attenuated receptor-binding mutants of staphylococcal enterotoxin A. J Infect Dis 1996, 174:338-345.

11. Lowell GH, Colleton C, Frost D, Kaminski RW, Hughes M, Hatch J, Hooper C, Estep J, Pitt L, Topper M, Hunt RE, Baker W, Baze WB: Immunogenicity and efficacy against lethal aerosol staphylococcal enterotoxin B challenge in monkeys by intramuscular and respiratory delivery of proteosometoxoid vaccines. Infect Immun 1996, 64:4686-4693.

12. Lowell GH, Kaminski RW, Grate S, Hunt RE, Charney C, Zimmer S, Colleton C: Intranasal and intramuscular proteosome-staphylococcal enterotoxin $B$ (SEB) toxoid vaccines: immunogenicity and efficacy against lethal SEB intoxication in mice. Infect Immun 1996, 64:1706-1713.

13. Eldridge JH, Staas JK, Meulbroek JA, Tice TR, Gilley RM: Biodegradable and biocompatible poly(DL-lactide-co-glycolide) microspheres as an adjuvant for staphylococcal enterotoxin B toxoid which enhances the level of toxin-neutralizing antibodies. Infect Immun 1991, 59:2978-2986.

14. Cui JC, Hu DL, Lin YC, Qian AD, Nakane A: Immunization with glutathione S-transferase and mutant toxic shock syndrome toxin 1 fusion protein protects against Staphylococcus aureus infection. FEMS Immunol Med Microbiol 2005, 45:45-51.

15. Hu DL, Omoe K, Narita K, Cui JC, Shinagawa K, Nakane A: Intranasal vaccination with a double mutant of staphylococcal enterotoxin $C$ provides protection against Staphylococcus aureus infection. Microbes Infect 2006, 8:2841-2848.

16. Cui JC, Zhang BJ, Lin YC, Wang QK, Qian AD, Nakane A, Hu DL, Tong GZ: Protective effect of glutathione S-transferase-fused mutant staphylococcal enterotoxin C against Staphylococcus aureus-induced bovine mastitis. Vet Immunol Immunopathol 2010, 135:64-70. 
17. Chang BS, Moon JS, Kang HM, Kim YI, Lee HK, Kim JD, Lee BS, Koo HC, Park YH: Protective effects of recombinant staphylococcal enterotoxin type $C$ mutant vaccine against experimental bovine infection by a strain of Staphylococcus aureus isolated from subclinical mastitis in dairy cattle. Vaccine 2008, 26:2081-2091.

18. Gupta RK: Aluminum compounds as vaccine adjuvants. Adv Drug Deliv Rev 1998, 32:155-172.

19. Singh M, Ugozzoli M, Kazzaz J, Chesko J, Soenawan E, Mannucci D, Titta F, Contorni M, Volpini G, Del Guidice G, O'Hagan DT: A preliminary evaluation of alternative adjuvants to alum using a range of established and new generation vaccine antigens. Vaccine 2006, 24:1680-1686.

20. Okada H, Toguchi H: Biodegradable microspheres in drug delivery. Crit Rev Ther Drug Carrier Syst 1995, 12:1-99.

21. Gupta RK, Singh M, O'Hagan DT: Poly(lactide-co-glycolide) microparticles for the development of single-dose controlled-release vaccines. Adv Drug Deliv Rev 1998, 32:225-246.

22. Close B, Banister K, Baumans V: Bernoth EM, Bromage N, Bunyan J, Erhardt W, Flecknell P, Gregory N, Hackbarth H, Morton D, Warwick C: Recommendations for euthanasia of experimental animals: Part 2. DGXT of the European Commission. Lab Anim 1997, 31:1-32.

23. Tremaine MT, Brockman DK, Betley MJ: Staphylococcal enterotoxin A gene (sea) expression is not affected by the accessory gene regulator (agr). Infect Immun 1993, 61:356-359.

24. Caputo A, Brocca-Cofano E, Castaldello A, De Michele R, Altavilla G, Marchisio M, Gavioli R, Rolen U, Chiarantini L, Cerasi A, Dominici S, Magnani M, Cafaro A, Sparnacci K, Laus M, Tondelli L, Ensoli B: Novel biocompatible anionic polymeric microspheres for the delivery of the HIV-1 Tat protein for vaccine application. Vaccine 2004, 22:2910-2924.

25. Jeyanthi R, Mehta RC, Thanoo BC, DeLuca PP: Effect of processing parameters on the properties of peptide-containing PLGA microspheres. J Microencapsul 1997, 14:163-174.

26. Jeffery H, Davis SS, O'Hagan DT: The preparation and characterization of poly(lactide-co-glycolide) microparticles. II. The entrapment of a model protein using a (water-in-oil)-in-water emulsion solvent evaporation technique. Pharm Res 1993, 10:362-368.

27. Singh $M$, Li XM, McGee JP, Zamb T, Koff W, Wang CY, O'Hagan DT: Controlled release microparticles as a single dose hepatitis $B$ vaccine: evaluation of immunogenicity in mice. Vaccine 1997, 15:475-481.

28. Igartua M, Hernandez RM, Esquisabel A, Gascon AR, Calvo MB, Pedraz LL: Enhanced immune response after subcutaneous and oral immunization with biodegradable PLGA microspheres. J Control Release 1998, 56:63-73.

29. Leitner G, Krifucks O, Kiran MD, Balaban N: Vaccine development for the prevention of staphylococcal mastitis in dairy cows. Vet Immunol Immunopathol 2011, 142:25-35

30. Pereira UP, Oliveira DG, Mesquita LR, Costa GM, Pereira L: Efficacy of Staphylococcus aureus vaccines for bovine mastitis: a systematic review. Vet Microbiol 2011, 148:117-124.

31. Younis A, Krifucks O, Heller ED, Samra Z, Glickman A, Saran A, Leitner G: Staphylococcus aureus exosecretions and bovine mastitis. J Vet Med $B$ Infect Dis Vet Public Health 2003, 50:1-7.

32. Stohl W: Elliott JE: Differential human T cell-dependent B cell differentiation induced by staphylococcal superantigens (SAg). Regulatory role for SAg-dependent B cell cytolysis. J Immunol 1995, 155:1838-1850.

33. Collins LV, Eriksson K, Ulrich RG, Tarkowski A: Mucosal tolerance to a bacterial superantigen indicates a novel pathway to prevent toxic shock. Infect Immun 2002, 70:2282-2287.

34. Cui Z, Mumper RJ: Microparticles and nanoparticles as delivery systems for DNA vaccines. Crit Rev Ther Drug Carrier Syst 2003, 20:103-137.

35. Jiang W, Gupta RK, Deshpande MC, Schwendeman SP: Biodegradable poly (lactic-co-glycolic acid) microparticles for injectable delivery of vaccine antigens. Adv Drug Deliv Rev 2005, 57:391-410.

36. Ribeiro S, Rijpkema SG, Durrani Z, Florence AT: PLGA-dendron nanoparticles enhance immunogenicity but not lethal antibody production of a DNA vaccine against anthrax in mice. Int J Pharm 2007, 331:228-232.

37. Shi L, Caulfield MJ, Chern RT, Wilson RA, Sanyal G, Volkin DB: Pharmaceutical and immunological evaluation of a single-shot hepatitis B vaccine formulated with PLGA microspheres. J Pharm Sci 2002, 91:1019-1035.
38. Tabata $Y$, Inoue $Y$, Ikada $Y$ : Size effect on systemic and mucosal immune responses induced by oral administration of biodegradable microspheres. Vaccine 1996, 14:1677-1685.

39. Cameron CM, Fuls WJ, Botha WF: Composition and evaluation of the efficacy of Staphylococcus aureus vaccine. Onderstepoort J Vet Res 1979, 46:1-8.

40. Brown EL, Dumitrescu O, Thomas D, Badiou C, Koers EM, Choudhury P, Vazquez V, Etienne J, Lina G, Vandenesch F, Bowden MG: The PantonValentine leukocidin vaccine protects mice against lung and skin infections caused by Staphylococcus aureus USA300. Clin Microbiol Infect 2009, 15:156-164.

41. Cook J, Hepler R, Pancari G, Kuklin N, Fan H, Wang XM, Cope L, Tan C, Joyce J, Onishi J, Montgomery D, Anderson A, McNeely T: Staphylococcus aureus capsule type 8 antibodies provide inconsistent efficacy in murine models of staphylococcal infection. Hum Vaccin 2009, 5:254-263.

42. Middleton JR, Luby CD, Adams DS: Efficacy of vaccination against staphylococcal mastitis: a review and new data. Vet Microbiol 2009, 134:192-198.

43. Diwan M, Elamanchili P, Lane H, Gainer A, Samuel J: Biodegradable nanoparticle mediated antigen delivery to human cord blood derived dendritic cells for induction of primary $\mathrm{T}$ cell responses. J Drug Target 2003, 11:495-507.

44. Choudary S, Ravikumar P, Ashok Kumar C, Suryanarayana W, Reddy GR: Enhanced immune response of DNA vaccine (VP1-pCDNA) adsorbed on cationic PLG for foot and mouth disease in guinea pigs. Virus Genes 2008, 37:81-87.

45. Thomas C, Gupta V, Ahsan F: Influence of surface charge of PLGA particles of recombinant hepatitis $B$ surface antigen in enhancing systemic and mucosal immune responses. Int J Pharm 2009, 379:41-50.

46. Saini V, Jain V, Sudheesh MS, Jaganathan KS, Murthy PK, Kohli DV: Comparison of humoral and cell-mediated immune responses to cationic PLGA microspheres containing recombinant hepatitis B antigen. Int J Pharm 2011, 408:50-57.

47. Huda T, Nair H, Theodoratou E, Zgaga L, Fattom A, El Arifeen S, Rubens C, Campbell $H$, Rudan I: An evaluation of the emerging vaccines and immunotherapy against staphylococcal pneumonia in children. BMC Public Health 2011, 11(Suppl 3):S27.

doi:10.1186/1297-9716-43-20

Cite this article as: Chen et al:: Protective effect of recombinant staphylococcal enterotoxin A entrapped in polylactic-co-glycolic acid microspheres against Staphylococcus aureus infection. Veterinary Research 2012 43:20.

\section{Submit your next manuscript to BioMed Central and take full advantage of:}

- Convenient online submission

- Thorough peer review

- No space constraints or color figure charges

- Immediate publication on acceptance

- Inclusion in PubMed, CAS, Scopus and Google Scholar

- Research which is freely available for redistribution

Submit your manuscript at www.biomedcentral.com/submit
C) Biomed Central 